\title{
PROMOTING SUSTAINABLE MOBILITY THROUGH CAR USE REDUCTION: THE IMPORTANCE OF SITUATIONAL FACTORS
}

\author{
FATAI YAKEEN ${ }^{* 1}$, SEYED MOHAMMADREZA GHADIRI ${ }^{1}$ AND RIZA TORKAN ${ }^{2}$
}

${ }^{1}$ School of Transportation and Logistics, Malaysia University of Science and Technology, No. 12, Jalan PJU 5/1, Kota Damansara, 47810 Petaling Jaya, Selangor Darul Ehsan, Malaysia. ${ }^{2}$ Torkan Muhendislik Co., Istanbul, Turkey.

*Corresponding author: abdulfatai02@yahoo.com

Submitted final draft: 21 January $2020 \quad$ Accepted: 1 May 2020

http://doi.org/10.46754/jssm.2020.08.013

\begin{abstract}
Rising car ownership and use worldwide is in several respects a threat to the environment. Transport researchers and policymakers have suggested and implemented policy measures to reduce car use and encouraged pro-environmental travel behaviour. The success or failure of these policies depends on a robust understanding of the factors influencing car use behaviour and most importantly situational factors facilitating car use. A sound understanding of the situational factors is the key to the effectiveness and success of car use reduction policies. This study examines the importance of car use facilitating situational factors in the promotion of sustainable mobility in urban areas. Data were obtained in a cross-sectional survey of 691 motorists in Lagos, Nigeria through purposive sampling technique, while the data analysis was done using partial least square structural equation modelling (PLS-SEM). The results indicated car access, time pressure and car use intention contributed $43 \%$ explained variance in car use behaviour. Car access had the largest direct effect on car use behaviour, followed by time pressure. Considering all the constructs in the model, car use intention was responsible for most of the variation in car use behaviour. The implications of the results from this study regarding the promotion of sustainable transportation and car use reduction are discussed.
\end{abstract}

Keywords: Sustainable transport, situational factor, car use, travel behaviour, travel demand management.

\section{Introduction}

Large investment in road transport infrastructure has led to car dominated cities even at the expense of public and active transportation modes (walking and cycling). Infrastructure such as roads and parking lots promotes greater use of the car and occupies a large amount of public space (Nieuwenhuijsen \& Khreis, 2019). Consequently, the car has become an essential part of our daily life and contemporary societies. It serves crucial roles in our economic, social, cultural and political lives as well as our wellbeing by facilitating movement, interaction and access to people and activities such as employment, health services, education etc (Garling \& Steg, 2007; Lucas, 2012; Khreis, 2016). Trips by private cars in urban areas around the world constitute about $50 \%$ of all trips and are estimated to reach 6.2 billion in 2025, twice its the number in 2005 .
A higher share of the growing trend will be in the developing nations (Verma et al, 2016). According to Wu et al (2016), by the year 2030, the rate of car use and car ownership in urban areas of China is estimated to reach 22.8 billion and 14.7 billion respectively. Car use has been associated with negative effects which include congestion, use of public spaces, noise, heat, emission of greenhouse gases, air pollution, lack of physical activity, stress due to driving time, lower psychological wellbeing and cognitive decline (Dons et al, 2013; Martin et al, 2014; Nieuwenhuijsen \& Khreis, 2016; Mattision, 2016; Bakarina et al, 2017). The increasing use of cars is a major threat to environmental quality through $\mathrm{CO} 2$ emission causing global warming and air pollution which might impair individual wellbeing through negative effects on health (Unal et al, 2019).

In light of the above challenges, effective transport policy instruments are in high 
demand, especially policies that encourage a mode shift from private to public modes of transport or policies that promote sustainable and environmentally friendly travel behaviour. Such policies are often referred to as Transport Demand Management and has been manifested through strategies such as Pull (Improved Mobility Options), Push (Transport Pricing and Car Use Restriction) and Psychological Strategies (Information, Education and Awareness) (Yakeen et al., 2019). However, given that situational factors tend to facilitate the use of private cars. There are difficulties associated with implementing transport policies towards changing travel behaviours such as public opposition and political infeasibility (Yakeen et al., 2019). Moreover, if policy measures are to contribute to the solution of environmental problems, it is important to consider the situational variables influencing car use behaviour. We cannot promote actions that benefit the environment without understanding what motivates or constrains them. The effectiveness of any strategy for behavioural change is dependent on which factors influence a particular behaviour. In general, strategies for behavioural change will be more effective if they address important factors influencing car use (Steg, 2016). Previous studies on car use behaviour focused on habit, socio-demographic and psychological factors influencing car use (Van Acker et al, 2010). There is a dearth of empirical research on situational factors. Also, the literature on the relationship between situational factors and car use behaviour has not been examined systematically and largely focused on car access. In addition, the available empirical studies were conducted in developed countries. There is lack of studies on situational factors influencing car use in developing countries especially in Africa. This study addresses these gaps on the premise that reducing car use can help to mitigate congestion, noise, accidents and also improve air quality. Moreover, if people switch to other modes, there may be improvements in public health and increased economic productivity (Dft, 2004). The main aim of this study is to examine the relationship between situational factors and car use behaviour.

\section{Theoretical Underpinning}

Research on situational influences on travel behaviour has been guided by the theory of planned behaviour (Ajzen, 1991; Ajzen \& Fishbein, 2005), the theory of interpersonal behaviour (Triandis, 1977), the Ipsative Theory of Behaviour (Tanner, 1999), the Comprehensive Action Determination Model (CADM) (Klockner and Blobaum, 2010) and the CAUSE framework (Chng et al., 2018).

The theory of planned behaviour is one of the most commonly used frameworks to understand human behaviour (Ajzen, 1991). According to the theory, the most important factor that determines the behaviour of an individual is his or her intention to perform that behaviour. The intention to carry out the behaviour is itself influenced by the attitude of the individual towards the behaviour, the subjective norm, and the level of perceived behavioural control. Attitude refers to an individual's subjective evaluation of a given behaviour or object, subjective norm refers to the social pressure a person perceives to carry out a particular behaviour and perceived behavioural control stands for the presence of factors that may facilitate or obstruct the implementation of behaviour. Like the theory of planned behaviour (TPB), the Theory of Interpersonal Behaviour (TIB) (Triandis, 1977) also defines intention as one of the influential factors of behaviour and it was proposed that habit, intention and facilitating conditions (situational factors) as be the three determinants of behaviour. Habit and intention interact with situational factors that either facilitate or inhibit behaviour.

The Ipsative Theory of Behaviour states that the behaviour of individuals may be influenced by constraints arising from the absence of objective or subjective favourable conditions imposed by the individual's internal as well as external situations (Tanner, 1999). Rather than focusing on reasons for action, the Ipsative 
theory considers the reasons for non-action. The theory pointed out that even though individuals have a positive attitude and intention towards action, they may not engage in such action due to situational constraints. Thus, situational constraints may prevent positive attitudes towards pro-environmental travel modes (such as public transport, cycling, walking) from being expressed in travel behaviour. Therefore, investigating commuters' mode choice should not focus only on psychological, socio-economic and demographic factors but also on situational factors.

In explaining the influences on proenvironmental behaviour, Klockner and Blobaum (2010) proposed the Comprehensive Action Determination Model (CADM). The authors combined constructs from the Ipsative Theory of Behaviour, the Theory of Planned Behaviour and the Norm Activation Model to form the Comprehensive Action Determination Model (CADM). According to the Comprehensive Action Determination Model, individual behaviour is directly determined by influences from three sources: intentional, situational and habitual, and indirectly by influences from normative sources.

In a review of 32 studies, Chng et al (2018) explored the psychological determinant of car use through the development of an integrative conceptual framework of antecedents of car use called the CAUSE framework. The CAUSE framework was formed from 15 psychological theories. In the framework, objective situational constraints were situated in the pre-action stage under the construct 'control' to show its relationship with car use (implementation) intention. This means that implementation intention about car use is influenced by the presence of access to the means to the behaviour. For instance, having access to a car would strongly influence one's ability to implement an intention to drive. Other constructs in the pre action stage are intention and habit.

\section{Situational Factors Influencing Car Use Behaviour}

Situational factors refers to the set(s) of circumstances or state of affairs that influence behavioural decisions

for e.g. travel mode choice (Klockner \& Friedrichmeier, 2011). Car use decision depends on how the situational factors affecting perceived benefits of the car are interpreted and understood by the user (Bamberg et al, 2011). Situational factors (influencing car use) mentioned in the literature include: car access or availability, time pressure, travelling together with family or friends, bad weather etc. However, most of the empirical studies focused on car access and time pressure with both constructs investigated separately. No study has investigated both car access and time pressure in one study or model. In this study, we focused on car access and time pressure based on availability of empirical studies and we integrated the two constructs into a model.

\section{Car Access or Availability}

Car access or availability occurs when a traveller has the option of using a car for a trip or a traveller perceives that for a particular trip, he could have used a car because any subsequent mode choice is made based on this perception. On the influence of car access on car use, Tanner (1999) explored the constraints influencing driving behaviour among car owners. The author used multiple regression analysis to analyse data collected from a sample of 153 Swiss adults. Objective situational constraints were measured using car availability and place of residence while driving frequency was used to measure driving behaviour. The study found that car availability/access is a significant predictor of driving frequency/behaviour.

Bamberg and Schmidth (2003) compared empirically the predictive power of the Norm Activation Model (NAM), the Theory of Planned Behaviour (TBP) and the Theory of Interpersonal Behaviour (TIB) in the context of car use for the university routes. Data from a 
questionnaire filled out by 254 students at the University of Giessen, Germany was analysed using structural equation modelling. Situational factors that might restrict or facilitate the car use for the University routes were measured by car ownership and car availability/access. The results of the TPB model revealed that control belief (car ownership and availability) have a significant and direct effect on actual car use. In the TIB model, control beliefs have a significant direct effect on car use intention.

Using an online survey of 430 students in three German cities (Bamberg, Greifswald and Regensburg), Klockner and Matthies (2009) tested the predictive power of NAM that integrates the constructs of perceived behavioural control (PBC), situational restraints and habits to explain students choice of means of transportation to the University. The study used car access and efforts required to use public transportation to represent situational restraints. The study found that car choice habits and car access had the strongest direct influence on actual car use by students for commuting to the University. The authors concluded that students with easy car access are likely to use the car for trips to the University.

Klockner and Blobaum (2010) used CADM of ecological behaviour to examine the effect of intentional, normative, situational and habitual influences on environmentally friendly behaviour. The model was tested on a sample of 389 students at the University of DuisburgEssen, Germany, in the domain of travel mode choice using a structural equation modelling approach. In the study, the authors used car access as a measure of objective situational factor facilitating car use with the proposition that easy car access facilitates car use. The results show that CADM explained the greatest degree of variation as compared to other models i.e. TPB, NAM and combination of TPB and NAM. Also, subjective situational constraint (perceived behavioural control) and objective situational constraint (car access) were responsible for most of the variation in travel mode choice (car use) in the CADM. The study found that situational factor (car access) has a significant and direct influence on car choice behaviour. The authors suggested that changing situational conditions through policy interventions is a promising way of modifying behaviour.

Using a multi-level approach to travel mode choice, Klockner and Friedrichmeier (2011) examined how people characteristics and situation-specific aspects determine car use in a sample of 3560 students of the RuhrUniversity in Bochum, Germany. The authors used structural equation modelling to analyse the determinants of travel mode choice on four frequent trips (i.e. trip to the University, to work, to a favourite leisure activity, and favourite shop). The study found that among the situational variables, having a car available (car access) for a specific trip has the strongest influence on car use.

\section{Time Pressure}

Time pressure can be defined as a feeling of time scarcity arising from people's perception that they have too much task to accomplish in 'too little time' (Garling et al, 2014). Time pressure is a product of time scarcity which can be described as the difference between time required to perform a task and the time available at one's disposal to carry out the activity (Rastegary \& Landy, 1993). The degree to which people perceived scarcity of time is that, the more they experience time pressure which causes changes in behaviour (Garling et al, 2014). Time pressure has been identified as one of the causes of angry and aggressive driving and one of the risk factors for accidents and risk taking by drivers and speed behaviour (Coeugnet et al, 2013). Cars being faster than other road transport modes are used to diminish time pressure due to its greater flexibility and its facilitation of driver's accomplishment of more activities in the same time frame.

Cars facilitate the rushing around of modern households while car use enables the combination of tasks in tight time frames (Hans, 2013). Time pressure in households where both 
parties work is greater and this leads to private car use. The combination of work and family leads to more people experiencing time pressure which eventually leads to more frequent use of private car (Dieleman et al, 2002). One of the reasons for increased car trips is time pressure (Jakobsson, 2007). The flexibility in time and space provided by the private car enables household members to cope with time pressure more efficiently (Limtanacool et al, 2006). Time spent waiting for public transport and the journey time act as disincentives for using public transport under time pressure. In a situation of time pressure, the main factors influencing travel mode choice behaviour are speed, flexibility and convenience and the travel mode with these features is the private car. The higher the time pressure, the higher the frequency of car use (Best \& Lanzerdorf, 2005). Time pressure is experienced by women more than men, especially working women. In trying to fulfil employment and household tasks, women experiences more time pressure and one of the strategies for coping with the time pressure is the use of private car which is considered a faster and convenient mode (Best \& Lanzerdorf, 2005). Time pressure also arises from work related time constraints such as penalty for late arrival at work which is related to work commuting. (Coeugnet et al, 2013). One of the keys to successful management of deadlines is having a fast means of transport (Hans, 2013).

In this study, we used car access and time pressure as a measure of objective situational factors facilitating car use. The intention which is a key determinant of behaviour is common to all the theories and is therefore included in the research model.

In this study, we investigated the validity of some of the situational facilitating factors to determine if they influence motorists' car use behaviour in a developing country. The following research hypotheses were tested in this study:

H1: Car access has a significant effect on car use intention.

$\mathrm{H} 2$ : Time pressure has a significant influence on car use intention.

H3: Car access has a significant relationship with car use behaviour.

H4: Time pressure has a significant association with car use behaviour.

H5: Car use intention has a significant impact on car use behaviour.

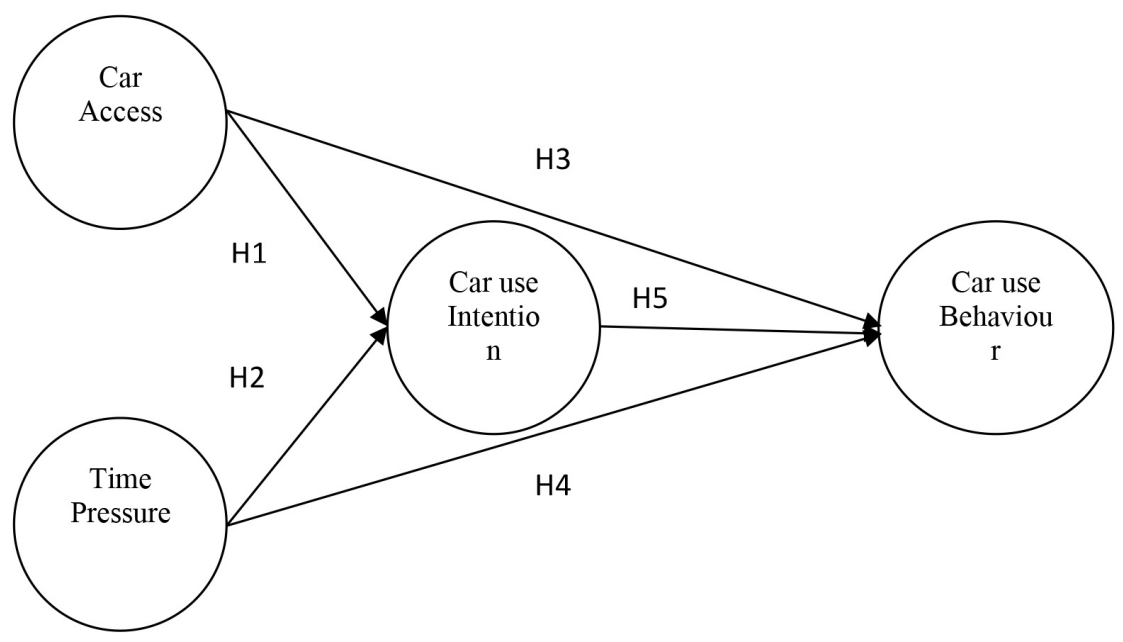

Figure 1: Research model 


\section{Materials and Methods}

\section{Study Area}

The location of this study is Lagos state, the smallest state in Nigeria with a total size area of 357,700 hectares and its city is the most populous in sub-Saharan Africa and is projected to become one of the largest megacities in the world by the year 2020 (LSTMP, 2009). Lagos is the economic and financial centre in Nigeria accounting for over $50 \%$ of the country's industrial and commercial establishments and $70 \%$ of manufacturing activities. As a port city, Lagos hosts Apapa, Tin Can Island, RO-RO and container ports. These ports collectively handle about $75 \%$ of Nigeria's imports and about $90 \%$ non-oil exports by weight (NBS, 2006). The state also hosts the Murtala Mohammed International Airport (MMA) which handles about $80 \%$ of air freights and passenger movements in and out of the country.

Furthermore, Lagos has extensive road and telecommunication network and as such is the prime destination of local and international migrants. The rapidly growing population of the city has placed intense pressure on existing transport infrastructure thereby affecting the efficiency and productivity level of the transport network with an adverse effect on urban transportation and environment. The existing public transport system in Lagos Metropolitan Areas is predominantly road-based (LASTMA, 2005). Other motorised transport modes such as rail and water are grossly underdeveloped, contributing $2 \%$ and $5 \%$ respectively to the traffic. Consequently, the road network suffers severe and chronic traffic congestion. Also, Lagos has a very high accident rate based on an international benchmark. The city is one of the most polluted cities in terms of air and noise pollution (LSTMP, 2009).

The demand for transport service is growing at a faster rate with Lagos generating about 10.5 million motorised trips daily and the current supply of roads in Lagos metropolis is inadequate to match the rising current and future demand for transport (LSTMP, 2009).

\section{Research Design and Data Collection}

This study used a quantitative, non-experimental survey and cross-sectional data to investigate the relationship between the variables. The unit of analysis is the individual car owners in Lagos State, Nigeria, while the population consists of motorists in the twenty local government areas in Lagos State. The focus is on car use for commuting. Eight hundred questionnaires were distributed to motorists across the twenty (20) local governments in Lagos State using purposive sampling technique. The sample size is in line with the requirement for using Partial Least Square- Structural Equation Modelling (which is adopted for data analysis in this study) as suggested by Hair, et al., (2016) that at least 59 observations are needed to achieve a statistical power of $80 \%$ for detecting R-Square value of at least 0.25 . Also, the "10 times rule" suggests that sample size should at least be equal to " 10 times the maximum number of structural paths pointing at a latent variable anywhere in the PLS path model" (in the case of this study $10 \times 3=$ 30) (Thompson, Barclay \& Higgins, 1995) .

\section{Measures of Constructs:}

The research instrument for this study was developed using measurement scales adapted from previous studies. The questionnaire was divided into two sections. In the first section, the participants were asked to provide information about their background data such as gender, age, income, level of education, employment status, employment type, marital status, number of children, number of car (s) and their local government. The second section contained the items for each of the constructs in the research model i.e. car access, time pressure, car use intention and car use behaviour. The wordings for the questionnaire items were adapted from the literature (Klockner \& Blobaum, 2010; Loukopoulos et al, 2004; Waqas et al, 2018; Ajzen, 2013). Changes were made to the selected items to make sure they fit into the context of this study. 
Car access: This construct was measured with four (4) items. The respondents indicated how often they encounter or experience the following situations: "Access to a private car at home", "Having a valid driving licence and vehicle documents", "Your private car being roadworthy and in good condition"," Having resources for fuelling and maintenance of your car". The responses were rated using a five-point scale ranging from "Never" (1) to "Always" (5).

Time pressure: Two items were used to measure time pressure. The two items were formulated as follows: How often you encounter or experience the following situations: "Being pressed for time due to demand of work or employment", "Being in a hurry due to pressure of combining work with family obligations". The responses were rated using a five-point scale ranging from "Never" (1) to "Always" (5).

Car use intention: The participants indicated whether they intend to adopt car as a commuting mode by responding to the two items: "I intend to use the car for my trips to work" and "I plan to use the car for my commuting trips". The responses were rated using a five-point scale ranging from "Strongly disagree" (1) to "Strongly agree" (5).

Car use behaviour: The constructs measure motorists' frequency of car use for commuting with the item: "How often do you use your car for commuting to and from work". The responses were rated using a five-point scale ranging from "Never" (1) to "Always" (5).

\section{Analysis}

To test the research model, this study used the partial least square (PLS) technique of Structural Equation Modelling using SmartPLS version 2.0. Based on the recommendation of Hair et al (2013), this study applied the two-step approach for data analysis. The first step analysed the measurement model, while the second evaluated the structural model. Besides, a descriptive analysis of respondents' background data was conducted using the Statistical Package for Social Sciences (SPSS) version 23.0. In addition, the SPSS was used to conduct Mann-Whitney U and Kruskal-Wallis Tests on the socio-economic and demographic variables of respondents to examine their effects on car use behaviour. The tests were considered as appropriate for the analysis because (i) the independent variables (Gender, Age, Income etc.) are measured on categorical scale, while the dependent variable (Car use behaviour) was measured on ordinal scale (ii) the tests aimed at testing for differences in the scores among the groups or categories (Pallant, 2016).

\section{Results}

This section presents the result of the field data. It begins with a discussion of the background characteristics of the participants. This is followed by the estimation of the measurement and structural model.

\section{Respondents' background information:} A summary of the characteristics of the participants under study is presented in table 1 . The participants were adults with the majority $(60 \%)$ aged between 35-54 years. In terms of gender, $68 \%$ of the participants are male while $32 \%$ are females. Most of the respondents (66\%) fall in category with an income of N50,000.00 N150,000.00. Regarding the level of education, most of the participants (52\%) were holders of first degree. In terms of employment status, $78 \%$ of the respondents were employed full time. Most of the participants (44\%) worked in the public sector, while $37 \%$ work in the private sector. Concerning the marital status of participants, $84 \%$ of them were married, while $40 \%$ of them representing the majority with three (3) children in the household. Regarding the number of car (s) in the household, the majority of the participants, $65 \%$, have only one (1) car.

A Mann-Whitney U Test was conducted to determine if the effect of gender on car use behaviour is different for males and females. The test revealed no significant difference in car use behaviour of males and females $(\mathrm{U}(691)=50,275.5 ; \mathrm{p}>.05)$. In addition, a 
Table 1: Background characteristics of study participants

\begin{tabular}{|c|c|c|}
\hline Demographic & Frequency $(n=691)$ & Percentage (\%) \\
\hline \multicolumn{3}{|l|}{ Gender } \\
\hline Male & 471 & 68.2 \\
\hline Female & 220 & 31.8 \\
\hline \multicolumn{3}{|l|}{ Age } \\
\hline Less than 25 years & 25 & 3.6 \\
\hline $25-34$ years & 133 & 19.2 \\
\hline $35-44$ years & 228 & 33.0 \\
\hline $45-54$ years & 189 & 27.4 \\
\hline $55-64$ years & 98 & 14.2 \\
\hline 65 years and over & 18 & 2.6 \\
\hline \multicolumn{3}{|l|}{ Income } \\
\hline Less than 50,000 & 72 & 10.4 \\
\hline $50,000-100,000$ & 198 & 28.7 \\
\hline $100,001-150,000$ & 257 & 37.2 \\
\hline $150,001-200,000$ & 114 & 16.5 \\
\hline More than 200,000 & 50 & 7.2 \\
\hline \multicolumn{3}{|l|}{ Employment Status } \\
\hline Employed (Full-time) & 542 & 78.4 \\
\hline Employed (Part-time) & 92 & 13.3 \\
\hline Unemployed & 6 & 9 \\
\hline Retired & 22 & 3.2 \\
\hline Student & 23 & 3.3 \\
\hline Homemaker & 6 & 0.9 \\
\hline \multicolumn{3}{|l|}{ Employment type } \\
\hline Public & 302 & 43.7 \\
\hline Private & 253 & 36.6 \\
\hline Self-employed & 114 & 16.5 \\
\hline Others/NGO & 22 & 3.2 \\
\hline \multicolumn{3}{|l|}{ Marital Status } \\
\hline Single & 88 & 12.7 \\
\hline Married & 577 & 83.5 \\
\hline Widow & 15 & 2.2 \\
\hline Divorced & 11 & 1.6 \\
\hline
\end{tabular}




\begin{tabular}{lcc}
\hline Number of Children & & \\
None & 91 & 13.2 \\
One & 81 & 11.7 \\
Two & 185 & 26.8 \\
Three & 273 & 39.5 \\
Four and above & 61 & 8.8 \\
Number of Car (s) & & \\
One & 448 & 64.8 \\
Two & 192 & 27.8 \\
Three & 36 & 5.2 \\
Four and above & 15 & 2.2 \\
\hline
\end{tabular}

Kruskal-Wallis Test was conducted to determine whether there were differences in car use behaviour among respondents across categories of age, income, number of children, number of cars, and employment status groups. The test revealed a statistically significant difference in car use across the age groups $X^{2}(5,691)=$ $20.895, \mathrm{p}=<.05$. The age groups (35-44 yrs. and 45-54 yrs.) recorded a higher car use, followed by the age group (65 years and over) and then the remaining age groups (Below 25 yr., 25-34 yr., 55-64 yr.). Also, the test revealed a statistically significant difference in car use across income groups $\mathrm{X}^{2}(4,691)=16.846, \mathrm{p}$ $=<.05$. The income groups $(100,001-150,000$; 150,001-200,000;> 200,000) recorded a higher car use than the remaining income groups $(<$ $50,000 ; 50,000-100,000)$. On the effect of the number of children on car use, the test revealed a statistically significant difference in car use by the number of children $X^{2}(4,691)=16.837, p=$ $<.05$. The groups (with two and three children) recorded a higher car use than the remaining groups. Further, the test revealed a statistically significant difference in car use by number of cars $\mathrm{X}^{2}(4,691)=12.843, \mathrm{p}=<.05$. The group (with one car) recorded a higher car use than the remaining groups. On the effect of employment status on car use, the test revealed a statistically significant difference in car use by employment status $\mathrm{X}^{2}(5,691)=19.471, \mathrm{p}=<.05$. The group (employed - full time) recorded a higher car use, followed by the groups (retired and homemaker) and then the remaining groups (employed - parttime, unemployed, student).

In Table 2, the means and standard deviations for the construct items are displayed. The items were assessed with responses ranging from 1 to 5 . Items with values greater than 3 indicate a favourable assessment while mean values less than 3 indicate an unfavourable assessment.

Table 2: Descriptive statistics of variables

\begin{tabular}{lcc}
\hline Variable & Mean & Standard Deviation \\
\hline Car access & 4.145 & 0.93625 \\
Time pressure & 2.84 & 1.0565 \\
Car use intention & 4.29 & 0.7915 \\
Car use behaviour & 4.26 & 0.904 \\
\hline
\end{tabular}

Measurement Model: Assessment of the measurement model involves a test for convergent validity and discriminant validity.

Convergent validity: Convergent validity is the degree to which multiple items used to measure the same construct agree. As suggested by Hair et al (2010), factor loadings, Composite Reliability (CR), and Average Variance Extracted (AVE) are used to assess convergent validity. The benchmark for convergent validity is that the loadings should be greater than 0.7 $(>0.7)$, the CR should be greater than 0.7 $(>0.7)$ and the AVE should be greater than 0.5 $(>0.5)$. However, Hair et al (2016) noted that 
researchers frequently obtain weaker factor loading (outer loadings) $(<0.7)$ in social sciences. The authors suggested that rather than automatically eliminating indicators when their outer loadings are below 0.7 , researchers should examine the effect of item removal on composite reliability and content validity of the construct, especially for outer loadings between 0.4 and 0.7. Indicators with weaker outer loadings $(0.40-0.70)$ are sometimes retained based on their contribution to content validity (Hair et al, 2016), while those with very low outer loadings (below 0.40) should be eliminated from the construct.

In Table 3, all the loadings are greater than 0.7 , all the composite reliability values are greater than 0.7, and all the Average Variance Extracted (AVE) values are greater than 0.5. Therefore, we can say the measures have sufficient convergent validity.

Discriminant validity: Discriminant validity is the degree to which items differentiate among constructs and measures distinct concepts by examining the correlations between the measures of potentially overlapping constructs. Items should load more on their constructs in the model, and the average variance shared between each construct and its measure should be greater than the variance shared between the construct and other constructs (Fornell \& Larcker, 1981; Compeau et al, 1999). The criteria for the assessment of discriminant validity are that the values in the diagonal should be higher than all other values in the row and column. In Table 4, it is obvious that the values in the diagonal are higher than other values in the rows and columns, thus we can conclude that the measurement has discriminant validity.

Structural Model: The testing of the structural model involves the assessment of the relationship between latent constructs and testing of the hypothesis. The t-values were generated through a bootstrapping procedure which involves the use of subsamples of 5000 taken from the original sample with replacement to give bootstrap standard errors, which in

Table 3: Constructs outer loadings, Average variance Extracted and Composite Reliability

\begin{tabular}{lcccc}
\hline Construct & Item & Loading & AVE & $\begin{array}{c}\text { Composite } \\
\text { Reliability }\end{array}$ \\
\hline Car access & CA01 & 0.82255 & 0.666331 & 0.888713 \\
& CA02 & 0.806351 & & \\
CA03 & 0.834784 & & \\
Car use behaviour & CA04 & 0.801044 & & \\
Car use intention & CUB & 1 & 1 & 1 \\
& CUI01 & 0.849857 & 0.721337 & 0.838112 \\
Time pressure & CUI02 & 0.848774 & & \\
& TP01 & 0.892887 & 0.778413 & 0.875386 \\
\hline
\end{tabular}

Table 4: Latent variable correlation with the square root of the AVE

\begin{tabular}{lccccc}
\hline & & CA & CUB & CUI & TP \\
\hline Car access & CA & $\mathbf{0 . 8 1 6 2 9 1}$ & & & \\
Car use behaviour & CUB & 0.344054 & $\mathbf{1}$ & & \\
Car use intention & CUI & 0.312432 & 0.627654 & $\mathbf{0 . 8 4 9 3 1 5 6}$ & \\
Time pressure & TP & 0.040668 & 0.098592 & -0.006126 & $\mathbf{0 . 8 8 2 2 7 7 2}$ \\
\hline
\end{tabular}


turn gives approximate t-values for significant testing of the structural path and the bootstrap result approximates the normality of data (Hair et al. 2011; Wong et al. 2012).

Non-parametric bootstrapping was applied with 5000 replications to examine the influence of situational factors (car access, time pressure) on commuters' car use behaviour. The results (see Table 5) of the structural model from the PLS output show a significant positive relationship between car access and car use intention (H1), a significant positive association between car access and car use behaviour (H3), a significant positive influence of time pressure on car use behaviour (H4), a significant positive effect of car use intention on car use behaviour (H5). However, the hypothesised relationship between time pressure and car use intention (H2) is not supported.

\section{Discussion}

The main aim of the study was to examine the influence of situational factors on car use behaviour. This study further examined whether there are differences in car use behaviour among respondents across categories of gender, age, income, number of children, number of cars, and employment status groups. Mann-Whitney U Test, Kruskal-Wallis Test were applied on the data. The tests revealed no significant difference in car use behaviour of males and females (U $(691)=50,275.5 ; p>.05)$. This result is in line with the findings of Orru et al (2019) which found no difference in car use behaviour by gender in
Sweden. Also, the test revealed a statistically significant difference in car use across the age groups $X^{2}(5,691)=20.895, p=<.05$. The age groups (35-44 and 45-54 years of age) recorded a higher car use, followed by the age group (65 years and over) and then the remaining age groups (Below 25 years, between 25-34 and 5564 years of age). This result is consistent with the findings of Acker and Witlox (2010) and Orru et al (2019). These studies revealed that with increasing age, the number of car trip decreased especially among the elderly due to limited financial resources. In addition, the test revealed a statistically significant difference in car use across income groups $\mathrm{X}^{2}(4,691)=16.846$, $\mathrm{p}$ $=<.05$. The income groups $(100,001-150,000$; $150,001-200,000 ;>200,000)$ recorded a higher car use than the remaining income groups $(<50$, $000 ; 50,000-100,000)$. This result is supported by the findings of Acker and Witlox (2010) and Jou and Chen (2014) which showed that as monthly income of each household increased their car use also increased. On the effect of the number of children on car use, the test revealed a statistically significant difference in car use by number of children $\mathrm{X}^{2}(4,691)=16.837, \mathrm{p}=<$ .05 . The groups (with two and three children) recorded a higher car use than the remaining groups. This result is aligned with the findings of Dieleman et al (2002) and Fallon et al (2004) which showed that presence of children in the household led to increase in the number of car trips. Further, the test revealed a statistically significant difference in car use by number of cars $\mathrm{X}^{2}(4,691)=12.843, \mathrm{p}=<.05$. The group

Table 5: Bootstrapping results

\begin{tabular}{cccccc}
\hline Hypothesis & Relationship & $\begin{array}{c}\text { Standardised } \\
\text { Beta }\end{array}$ & $\begin{array}{c}\text { Standard } \\
\text { Error } \\
\text { (STERR) }\end{array}$ & $\begin{array}{c}\text { T Statistics } \\
(\mid \mathbf{O} / \text { STERR|) }\end{array}$ & Decision \\
\hline H1 & CA -> CUI & 0.313199 & 0.040089 & 7.812648 & Supported \\
H2 & TP -> CUI & -0.018863 & 0.038032 & 0.495979 & Not supported \\
H3 & CA -> CUB & 0.159445 & 0.039188 & 4.06869 & Supported \\
H4 & TP -> CUB & 0.095652 & 0.029436 & 3.249473 & Supported \\
H5 & CUI -> CUB & 0.578425 & 0.033531 & 17.250559 & Supported \\
\hline
\end{tabular}


(with one car) recorded a higher car use than the remaining groups. This is contrary to the finding of Hunecke et al (2007) which showed that the higher the number of cars the higher the car trips. The difference in the findings may be because in our data majority of the respondents (65\%) have only one car. On the effect of employment status on car use, the test revealed a statistically significant difference in car use by employment status $\mathrm{X}^{2}(5,691)=19.471, \mathrm{p}=<$ .05 . The group (employed - full time) recorded a higher car use, followed by the groups (retired and homemaker) and then the remaining groups (employed - part-time, unemployed, student). These findings are aligned with the study by Fallon et al (2004) which revealed that parttime employees were less likely to drive than full-time employee; students were less likely to drive than working adults.

The results of the Structural Equation Modelling (SEM) imply that as motorists' car access increases by a unit, their car use intention increases by 0.31 (31\%), thus motorists having easy access to private cars will have strong car use intention. This is consistent with the findings of Klockner and Blobaum (2010). Also, the results show that for every unit increase in motorists' car access, car use behaviour increases by $0.16(16 \%)$, meaning that car commuters with easy access to private cars will have high car use frequency. This is in-line with the results from previous studies which found a significant interaction between car access and car use behaviour (Klockner \& Blobaum, 2010; Klockner \& Friedrichmeier, 2011).

Regarding time pressure, the results show that there is no significant relationship between time pressure and car use intention. However, time pressure has a significant positive influence on car use behaviour, implying that a unit increase in motorists' time pressure causes a $0.10(10 \%)$ increase in their car use frequency, meaning that motorists who perceive more time pressure will have a high frequency of car use. No prior empirical research has examined the relationship between time pressure and car use behaviour. Thus, the support established for H4 that time pressure is positively related to car use behaviour is a new empirical finding.

Furthermore, the result reveals that car use intention has a significant positive influence on car use behaviour. A unit increase in car use intention leads to $0.58(58 \%)$ increase in car use frequency. This implies that car use intention has the strongest impact on car use behaviour. This result is consistent with the findings by Klockner and Blobaum (2010).

Based on the results above, this study has shown that when the motorists have easy access to a private car, the stronger their car use intention, the higher their car use frequency is. Also, the result indicated that motorists that perceived more time pressure will have high car use frequency for commuting.

Thus, policymakers and transport planners need to develop car use reduction policies such as push measures (e.g. car use pricing, car use restriction), pull measures (e.g. improvement of non-car travel modes), and psychological measures (e.g. information, education and awareness on the negative impact of car use). These policies have proven to be effective in reducing car use, based on evidence from the literature.

\section{Conclusion}

This study examines the influence of car use facilitating situations on motorists' car use behaviour. Overall, the results show that car access has a significant positive effect on car use intention and car use behaviour. Also, time pressure has a significant positive impact on car use behaviour, while car use intention has the strongest significant positive influence on car use behaviour. However, time pressure has no significant relationship with car use intention.

This study demonstrated the important role of car use facilitating situational factors in encouraging car use. At the point of deciding on a travel mode choice, any of the situational variables may be a barrier to using non-car mode and a facilitator of private car use. Changing travel behaviour motivated by car use 
facilitating situations will require an effective intervention. Since the facilitating factors may be specific to the individual, the behaviour or the situation, a combination of interventions may be required given that empirical research from the literature suggested that combination of transport policy packages is more effective. Such policies include car use restriction, alternative mobility improvement, education and advertising campaigns to raise awareness of the negative impact of widespread car use on individuals.

The results of this study have implications for transport policy. To encourage sustainable and pro-environmental travel behaviour, reduce congestion and mitigate the negative effect of car use, policymakers should implement travel demand management (TDM) strategies. For motorists' with easy access to private cars, TDM strategies such as car use pricing and car use restriction may be effective in discouraging car use. Similarly, for motorists with more time pressure, TDM measures such improvement of non-car travel modes (e.g. public transport) in terms of reduced travel time may be effective in discouraging motorists with more time pressure and encourage them to use public transport. The limitations of this study relates to the use of self-report. In future studies situational factors could be measured independently of the participants/respondents' perception i.e. through observation, to truly capture the objective situational influences.

\section{Acknowledgements}

\section{References}

Ajzen, I. (1991). The theory of planned behaviour. Organizational Behaviour and Human Decision Processes, 50(2), 179211.

Ajzen, I. (2013). Theory of planned behaviour questionnaire. Measurement Instrument Database for the Social Science. Retrieved from www.midss.ie.
Ajzen, I., \& Fishbein, M. (2005). The influence of attitudes on behaviour. The Handbook of Attitudes, 173(221), 31.

Bakrania, K., Edwardson, C. L., Khunti, K., Bandelow, S., Davies, M. J., \& Yates, T. (2017). Associations between sedentary behaviours and cognitive function: crosssectional and prospective findings from the UK Biobank. Am. J. Epidemiol., 187(3), 441-454. https://doi.org/10.1093/aje/kwx 273.

Bamberg, S., \& Schmidt, P. (2003). Incentives, morality, or habit? Predicting students' car use for university routes with the models of Ajzen, Schwartz, and Triandis. Environment and behaviour, 35(2), 264-285.

Bamberg, S., Fujii, S., Friman, M., \& Garling, T. (2011). Behaviour theory and soft transport measures. Transport Policy, 18(1), 228 -253 .

Barclay, D. W., Higgins, C. A., \& Thompson, R. (1995). The partial least squares approach to causal modelling: Personal computer adoption and use as an illustration. Technology Studies, 2, 285-309.

Belk, R. W. (1974). An exploratory assessment of situational effects on buyer behaviour. Journal of Marketing Research, 11(2), 156163.

Best, H., \& Lanzendorf, M. (2005). Division of labour and gender differences in metropolitan car use: An empirical study in Cologne, Germany. Journal of Transport Geography, 13(2), 109-121.

Carter, N. (2003). The politics of the environment: Ideas, activism, policy. Cambridge: Polity Press.

Chng, S., Abraham, C., White, M. P., Hoffmann, C., \& Skippon, S. (2018). Psychological theories of car use: An integrative review and conceptual framework. Journal of Environmental Psychology, 55, 23-33.

Cougnet, S., Naveteur, J., Antoine, P., \& Anceaux, F. (2013). Time pressure and driving: Work, emotions and 
risks. Transportation Research Part F: Traffic Psychology and Behaviour, 20, 3951.

Compeau, D., Higgins, C. A., \& Huff, S. (1999). Social cognitive theory and individual reactions to computing technology: A longitudinal study. MIS quarterly, 145-158.

DfT (Department for Transport). (2004). "The Future of Transport: A network for 2030", UK Government transport White Paper, accessed at http://www.dft.gov. uklstellentlgroups/dft_ about documents/ page/DFT about_031286. Pdf

Dieleman, F. M., Dijst, M., \& Burghouwt, G. (2002). Urban form and travel behaviour: Micro-level household attributes and residential context. Urban studies, 39(3), 507-527.

Dons, E., Temmerman, P., Van Poppel, M., Bellemans, T., Wets, G., \& Int, Panis L. (2013). Street characteristics and traffic factors determining road users' exposure to black carbon. Sci. Total Environ., 447, 72-79. https://doi.org/10.1016/j. scitotenv.2012.12. 076.

Fatai A. Yakeen, Seyed Mohammadreza Ghadiri, \& Reza Torkan. (2019). Factors influencing motorists' acceptability of transport demand management measures: A review. International Journal of Civil Engineering and Technology, 10(12), 406-415.

Fishbein, M., \& Ajzen, I. (1975). Belief, attitude, intention, and behaviour: An introduction to theory and research. Reading, MA: Addison-Wesley.

Fornell, C., \& Larcker, D. F. (1981). Structural equation models with unobservable variables and measurement error: Algebra and statistics.

Gärling, T., \& Schuitema, G. (2007). Travel demand management targeting reduced private car use: Effectiveness, public acceptability and political feasibility. Journal of Social Issues, 63(1), 139-153.
Gärling, T., \& Steg, L. (2007). Threats from car traffic to the quality of urban life: Problems, causes and solutions. Bingley: Emerald Group Publishing Limited.

Gärling, T., Eek, D., Loukopoulos, P., Fujii, S., Johansson-Stenman, O., Kitamura, R., Pendyala, R., \&

Vilhelmson, B. (2002). A conceptual analysis of the impact of travel demand management on private car use. Transport Policy, 9, 5970 .

Gärling, T., Krause, K., Gamble, A., \& Hartig, T. (2014). Emotional well-being and time pressure. PsyCh journal, 3(2), 132-143.

Guiver, J. W. (2007). Modal Talk: A Discourse analysis of how people talk about bus and car travel. Transportation Research, 41, $233-248$.

Hair Jr, J. F., Black, W. C., Babin, B. J., \& Anderson, R. E. (2010). Multivariate data analysis. vectors. (7th ed.).

Hair Jr, J. F., Hult, G. T. M., Ringle, C., \& Sarstedt, M. (2016). A primer on partial least squares structural equation modeling (PLS-SEM). Sage publications.

Hair, J. F., Ringle, C. M., \& Sarstedt, M. (2011). PLS-SEM: Indeed a silver bullet. Journal of Marketing Theory and Practice, 19(2), 139-152.

Hair, J. F., Ringle, C. M., \& Sarstedt, M. (2013). Partial least squares structural equation modelling: Rigorous applications, better results and higher acceptance. Long-range planning, 46(1-2), 1-12.

Hartgen, D. T. (1974). Attitudinal and situational variables influencing urban mode choice: Some empirical findings. Transportation, 3, 377-92.

Hunecke, M., Haustein, S., Grischkat, S., \& Böhler, S. (2007). Psychological, sociodemographic, and infrastructural factors as determinants of ecological impact caused by mobility behavior. Journal of Environmental Psychology, 27(4), 277-292. 
Jakobsson, C. (2007). Instrumental motives for private car use. Threats to the quality of urban life from car traffic: Problems, causes, and solutions, 205-218.

Jeekel, H., \& Rijkswaterstaat, P. O. (2014). Time, time scarcity and car mobility. In 13th world conference on transport research.

Jou, R. C., \& Chen, T. Y. (2014). Factors affecting public transportation, car, and motorcycle usage. Transportation research part A: policy and practice, 61, 186-198.

Khreis, H., Warsow, K. M., Verlinghieri, E., Guzman, A., Pellecuer, L., Ferreira, A., et al. (2016). The health impacts of traffic-related exposures in urban areas: Understanding real effects, underlying driving forces and co-producing future directions. Journal of Transport \& Health, 3(3), 249-267.

Klöckner, C. A., \& Blöbaum, A. (2010). A comprehensive action determination model - towards a broader understanding of ecological behaviour using the example of travel mode choice. Journal of Environmental Psychology, 30(4), 574586.

Klöckner, C. A., \& Friedrichsmeier, T. (2011). A multilevel approach to travel mode choice - how person characteristics and situationspecific aspects determine car use in a student sample. Transportation Research Part F: Traffic Psychology and Behaviour, 14(4), 261-277.

Klöckner, C. A., \& Matthies, E. (2009). Structural modeling of car use on the way to the university in different settings: Interplay of norms, habits, situational restraints, and perceived behavioral control 1. Journal of Applied Social Psychology, 39(8), 18071834.

Lagos Strategic Transport Masterplan. (2009).

LASTMA. (2005). Transportation Management in Nigeria.

Limtanakool, N., Dijst, M., \& Schwanen, T. (2006). The influence of socioeconomic characteristics, land use and travel time considerations on mode choice for mediumand longer-distance trips. Journal of transport geography, 14(5), 327-341.

Line, T. (2008). The attitudes of young people towards transport in the context of climate change. Unpublished $\mathrm{PhD}$ thesis, University of the West of England, Bristol.

Loukopoulos, P., Jakobsson, C., Gärling, T., Schneider, C. M., \& Fujii, S. (2004). Car-user responses to travel demand management measures: Goal setting and choice of adaptation alternatives. Transportation Research Part D: Transport and Environment, 9(4), 263-280.

Lucas, K. (2012). Transport and social exclusion: Where are we now? Transport Policy, 20, 105-113.

Martin, A., Goryakin, Y., \& Suhrcke, M. (2014). Does active commuting improve psychological wellbeing? Longitudinal evidence from eighteen waves of the British Household Panel Survey. Prev. Med., 69, 296-303. https://doi.org/10.1016/j. ypmed.2014.08. 023.

Mattisson, K., Jakobsson, K., Håkansson, C., et al., (2016). Spatial heterogeneity in repeated measures of perceived stress among car commuters in Scania, Sweden. Int. J. Health Geogr., 15(1), 22. https://doi. org/10.1186/s12942-016-0054-8.

Miller, G. T., \& Spoolman, G. E. (2009). Living in the environment: principles, connections, and solutions. Belmont, CA: Brookes/Cole Cengage Learning.

National Bureau of Statistics (NBS). (2006). Annual Abstract of Statistics.

Nieuwenhuijsen, M., \& Khreis, H. (2019). Integrating human health into the urban development and transport planning agenda: A summary and final conclusions. In Integrating human health into urban and transport planning (pp. 707-718). Cham: Springer.

Nieuwenhuijsen, M. J., \& Khreis, H. (2016). Car-free cities: Pathway to healthy urban 
living. Environ. Int., 94, 251-262. https:// doi.org/10.1016/j.envint.2016.05.032

O'Fallon, C., Sullivan, C., \& Hensher, D. A. (2004). Constraints affecting mode choices by morning car commuters. Transport Policy, 11(1), 17-29.

Orru, K., Poom, A., \& Nordlund, A. (2019). Socio-structural and psychological factors behind car use: Comparing Northern and Eastern Europe. Transportation Research Part A: Policy and Practice, 119, 313-325.

Pallant, J. S. P. S. S. (2016). Survival manual: A step by step guide to data analysis using SPSS program.

Rastegary, H., \& Landy, F. J. (1993). The interactions among time urgency, uncertainty, and time pressure. In O. Svenson \& A. J. Maule (Eds.), Time pressure and stress in human judgment and decision making (pp. 217-235). New York: Plenum Press.

Steg, L. (2016). Factors influencing the acceptability and effectiveness of transport pricing. In Acceptability of Transport Pricing Strategies. Published online: 04 Feb 2016; 187-20233

Tanner, C. (1999). Constraints on environmental behaviour. Journal of Environmental Psychology, 19, 145e215.

Tim Schwanen Karen Lucas. "Understanding Auto Motives" In Auto Motives. Published online: 28 Jan 2016; 3-38.

Triandis, H. C. (1977). Interpersonal behaviour. Monterey: Brooks/Cole.

Ünal, A. B., Steg, L., \& Granskaya, J. (2019). "To support or not to support, that is the question". Testing the VBN theory in predicting support for car use reduction policies in Russia. Transportation Research Part A: Policy and Practice, 119, 73-81.
Van Acker, V., \& Witlox, F. (2010). Car ownership as a mediating variable in car travel behaviour research using a structural equation modelling approach to identify its dual relationship. Journal of Transport Geography, 18(1), 65-74.

Van Acker, V., van Wee, B., \& Witlox, F. (2010). When transport geography meets social psychology: Toward a conceptual model of travel behaviour. Transport Reviews, 30(2), 219-240.

Verma, M., Manoj, M., \& Verma, A. (2016). Analysis of the influences of attitudinal factors on car ownership decisions among urban young adults in a developing country like India. Transp. Res. F: Traffic Psychol. Behav., 42, 90-103. http://dx.doi. org/10.1016/j.trf.2016.06.024

Waqas, M., Dong, Q. L., Ahmad, N., Zhu, Y., \& Nadeem, M. (2018). Understanding acceptability towards Sustainable Transportation Behavior: A case study of China. Sustainability, 10(10), 3686.

Whitmarsh, L., \& O’Neill, S. (2010). Green identity, green living? The role of pro-environmental self-identity in determining consistency across diverse pro-environmental behaviours. Journal of Environmental Psychology, 30, 305-314.

Wong, K. K. K. (2013). Partial least squares structural equation modelling (PLS-SEM) techniques using SmartPLS. Marketing Bulletin, 24(1), 1-32.

Wright, C., \& Curtis, B. (2005). Reshaping the motor car. Transport Policy, 12(1), 11-22.

Wu, N., Zhao, S., \& Zhang, Q. (2016). A study on the determinants of private car ownership in China: Findings from the panel data. Transp. Res. A: Policy Practice, 85, 186-195. http://dx.doi.org/10.1016/j. tra.2016.01.012. 